\title{
Turkish Adaptation of Attention Function Index: A Validity and Reliability Study
}

\author{
Nese Uysal ${ }^{1}$ (D) Gulcan Bagcivan ${ }^{2}$ (D) Filiz Unal Toprak ${ }^{3}$ (D) Yeter Soylu ${ }^{4}$ (D) Bektas Kaya ${ }^{4}$ (C) \\ ${ }^{1}$ Amasya University, Faculty of Health Sciences, Amasya, Turkey. \\ ${ }^{2}$ Koç University School of Nursing, Istanbul, Turkey. \\ ${ }^{3}$ Bolu Abant İzzet Baysal University, Faculty of Health Science, Bolu, Turkey. \\ ${ }^{4}$ Ankara Oncology Education and Training Hospital, Ankara, Turkey. \\ Correspondence Author: Neşe Uysal \\ E-mail: uysaln2007@hotmail.com \\ Received: 30.03.2020 Accepted: 15.02.2021
}

\begin{abstract}
Objective: Many cancer survivors have cognitive problems with concentration and memory after cancer treatment. The Attention Function Index (AFI) is a tool developed to evaluate cognitive processes in cancer patients. The purpose of this study was to investigate the adaptation of AFI in Turkish.

Methods: This methodological study was conducted with one hundred breast cancer survivors. Data were collected using the information form, AFI, and the European Organization for Research and Treatment of Cancer Quality of Life (EORTC QLQ-C30) scale. Internal consistency, testretest, and item-total scores were analyzed to assess the reliability of the AFI Turkish form.

Results: The internal consistency coefficient (Cronbach's alpha) was 0.89 for the Turkish version of AFI. Confirmatory factor analysis for construct validity revealed that the original three-factor structure of AFI was not confirmed, but the two-factor structure of the AFI was confirmed by the fit indices. In the correlation analysis for criterion validity, a statistically significant and positive relationship was found between AFI total scores and EORTC QLQ-C30 total scores. There was a strong positive correlation between test and retest scores $(r=0.524 ; p<0.01)$.

Conclusions: In this study, it was determined that the two-factor, 10-item version of the AFI, which was evaluated for validity and reliability, was well-matched with the sample in which the scale was administered. The Turkish version of AFI is a valid and reliable tool for breast cancer survivors. The scale tested in cancer survivors and can be used in clinical practice.
\end{abstract}

Keywords: Attention function, breast cancer, survivor, validity and reliability.

\section{INTRODUCTION}

Cognitive functions include high brain activities such as consciousness, attention, learning, memory, problem solving, decision making and calculation (1). Cognitive changes have been reported in $75 \%$ of patients receiving chemotherapy or radiation therapy. In addition, approximately one-third of cancer patients continue to experience cognitive problems even years after treatment $(2,3,4,5)$. Cognitive functioning is affected many factors such as the psychological burden of cancer, biological factors related to the disease, side effects of cancer treatment, stress, and depression in cancer patients. The most affected cognitive domain in cancer patients have been reported as psychomotor function, learning, memory, attention and concentration $(6,7)$.

Focus and attention capacity are essential for effective cognitive functioning. Attention is defined as the concentration of the mind on an object or thought, despite other stimuli that occur simultaneously (8). Attention, which is an organizing power for all behaviors, is effective in all cognitive areas such as getting information, maintaining and completing an activity, learning, solving problems, and interpersonal communication Selective attention is a basic cognitive capacity that provides greater sensitivity to important environmental stimuli $(9,10,11)$. Directed attention allows the individual to concentrate on a particular object, thought or problem. Individuals can process information efficiently and act purposefully through attention $(10,11)$. When cognitive processes related to attention functions are disrupted, individuals have difficulty in performing plans and activities, making decisions, remembering and maintaining daily life routines in general. These cognitive deficiencies lead to significant problems in the social and occupational functioning of the patients. Therefore, in recent years, studies have focused on the evaluation of cognitive functions in cancer patients $(9,10,11)$.

Neuropsychological tests that assess attention, memory, and processing speed are used in the assessment of cognitive disorders caused by cancer treatment $(12,13)$. However, it is stated in the literature that clinicians need more information to diagnose cognitive problems. The best way to assess cognitive functions is to measure the patient's perception of 
his or her cognitive function. There are few tools to determine how cognitive dysfunction develops loss of activity in cancer patients.

Although research has been conducted on perception, memory and concentration problems, fewer studies have examined the impact of these perceived problems on the daily functioning of patients. This study aimed to evaluate the Turkish adaptation and validation of the Attention Function Index (AFI), which is a measurement tool to identify cognitive problems related to cancer and its treatment.

\section{METHODS}

\subsection{Study Population}

This methodological study was carried out with breast cancer survivors who applied to a Training and Research Hospital Oncology Polyclinic between April and July 2019. In calculating the sample size, the formula that the validity and reliability of the scale should be 5 to 10 times the number of items in the scale was used. For this purpose, one hundred breast cancer survivors were included in the study for the validity and reliability of AFI with 13 items. Individuals who completed breast cancer treatment at least 6 months ago, aged between 18 and 65, who accepted to participate in the study and who could read and write Turkish were included in the study. Individuals who received palliative treatment, who had pre-existing depressive or psychotic disorders, and who had used any psychoactive drug were not included in the study.

\subsection{Measures}

Data were collected using the information form, AFI, European Organization for Research and Treatment of Cancer Quality of Life Scale (EORTC QLQ C30). Data were collected by face-to-face interview method in the polyclinic waiting room. Data collection took an average of 10-15 minutes. For the test-retest reliability of the scale, 20 patients were re-administered AFI two weeks after initial data collection. The information form prepared by the researchers consisted of questions about demographics. EORTC QLQ-C30 scale determines the quality of life in cancer patients. The scale includes three subscales: general well-being, functional scale and symptom scale, and 30 questions. High scores on functional scales and general health status scores indicate good health status, while high scores on symptom scale indicate excess symptoms. The validity and reliability of the scale in our country were made by Demirci et al (14).

Attention Function Index is a tool developed to evaluate cognitive processes in cancer patients. AFI was developed to assess the perceived effectiveness of the individual in performing tasks and activities that require selective attention and working memory (10). Initially, AFI was developed as 16 questions and used in different populations, but then reduced to 13 items based on the results of factor analysis. The scale consists of three sub-dimensions: attentional lapses, effective action, and interpersonal effectiveness. Effective action evaluates the perceived function of the person during daily life activities that require mental effort. Attentional lapses assesses perceived difficulties during jobs that require concentration. Interpersonal effectiveness measures how people perceive their interaction in specific situations and events that need attention.

In calculating the total score, the questions 10 to 13 are reversed. Total scores are calculated as the average of each item score totals. Higher scores mean better performance and indicate less attention deficit (10).

\subsection{Translation of the AFI}

We received permission from the author who developed the scale by e-mail for translation and adaptation of the scale into Turkish. Content validity was confirmed by 5 experts (1 psychologist, 2 clinician nurses, 1 radiation oncologist, 1 academician nurse). The English-language version of the AFI was translated into Turkish. The AFI scale was evaluated by the experts and the intelligibility, vocabulary and cultural structure of the questions were reviewed. The expert group discussed and commented on this version of the AFI. Then AFI was translated into English by the professional translator. The scale was applied to 10 patients and the intelligibility of the questions was tested prior to the application.

The relationship between AFI scores and EQORTC QLQ C30 scale was evaluated for the criterion validity. It was predicted that there was a significant positive relationship between the Turkish version of AFI and EORTC-QLQ C30 scores. Confirmatory factor analysis (CFA) was used to assess whether the original structure of AFI was validated for the sample in this study. The internal consistency coefficient was calculated for the reliability analysis of AFI. In order to determine the in variance of AFI over time, in-class correlation analysis was performed between test and retest total scores. Item total score correlation analysis was used to determine the items to be extracted in the Turkish version of the AFI.

\subsection{Ethical Statements}

All procedures in the study were carried out in accordance with the Helsinki Declaration. The study has been approved by the Ankara Oncology Education and Training Hospital Clinical Research Ethical Committee (2019-03/224). Written consents were obtained to the participants after the purpose of the study was explained.

\subsection{Statistical analysis}

Statistical analyses were performed in IBM SPSS for Windows Version 21.0. Numerical variables are summarized as frequency, mean \pm standard deviation and median [minimummaximum]. The Turkish version of the scale was developed by translate-back translate method in the assessment of language validity. For the construct validity of the scale, confirmatory 
factor analysis (CFA) was performed with Structural Equation Modeling in Amos 22.0 program. Cronbach Alpha coefficient was used for internal consistency and in-class correlation analysis was performed for test-retest analysis. Pearson correlation analysis was used for the validity of the criteria.

\section{RESULTS}

The average age of breast cancer survivors was $53.21 \pm$ 12.14 years, $69 \%$ were married and $58 \%$ were primary school graduates. $43 \%$ of participants were diagnosed 1 year ago and $70 \%$ completed treatment 6 months ago. Surgical treatment was applied to $91 \%$ of the participants and the most recent treatment for $51 \%$ was chemotherapy. $64 \%$ of participants do not have any other chronic disease except cancer (Table 1).

Table 1. Characteristics of survivors

\begin{tabular}{|c|c|c|}
\hline \multicolumn{3}{|l|}{ Characteristics } \\
\hline Age (years; mean $\pm S D$ ) & \multicolumn{2}{|c|}{$53.21 \pm 12.14$} \\
\hline & $n$ & $\%$ \\
\hline \multicolumn{3}{|l|}{\begin{tabular}{|l} 
Marital status \\
\end{tabular}} \\
\hline Married & 69 & 69 \\
\hline Single & 31 & 31 \\
\hline \multicolumn{3}{|l|}{ Educational status } \\
\hline Primary education & 58 & 58 \\
\hline High school & 26 & 26 \\
\hline University & 16 & 16 \\
\hline \multicolumn{3}{|l|}{ Time of diagnosis } \\
\hline 0-6 months & 43 & 43 \\
\hline 7-12 months & 37 & 37 \\
\hline Over 12 months & 20 & 20 \\
\hline \multicolumn{3}{|l|}{ Time after treatment } \\
\hline $0-3$ months & 70 & 70 \\
\hline 4-7 months & 16 & 16 \\
\hline 8-12 months & 7 & 7 \\
\hline Over 12 months & 7 & 7 \\
\hline \multicolumn{3}{|l|}{ Surgery } \\
\hline Yes & 91 & 91 \\
\hline No & 9 & 9 \\
\hline \multicolumn{3}{|c|}{ The last treatment received } \\
\hline Chemotherapy & 51 & 51 \\
\hline Radiotherapy & 28 & 28 \\
\hline Surgery & 20 & 20 \\
\hline Hormone therapy & 1 & 1 \\
\hline \multicolumn{3}{|l|}{ Chronic disease } \\
\hline Yes & 36 & 36 \\
\hline No & 64 & 64 \\
\hline
\end{tabular}

SD: standard deviation

\subsection{Reliability Analysis}

The Cronbach Alpha coefficient calculated for the 13 items in the Attention Function Index was 0.871. "Effective action" Cronbach Alpha coefficient was 0.933, "attentional lapses" Cronbach Alpha coefficient was 0.848 and the "interpersonal effectiveness" Cronbach Alpha coefficient was 0.416 .
Attention Function Index (AFI) total score was $6.61 \pm 1.08$ and the retest AFI total score was $6.66 \pm 0.96$. The intraclass correlation coefficient calculated between AFI total and retest total scale scores was $0.90(p \leq 0.001)$. As a result of item-total score correlation analysis for AFI, Cronbach's alpha value increased when item 9 and item 13 were erased (0.0885 for item 9 and 0.882 for item 13) (Table 3).

Table 2. Multi-factor model confirmatory factor analysis and fit indices of $\mathrm{AFI}$

\begin{tabular}{|l|c|c|c|c|}
\hline $\begin{array}{c}\text { Fit } \\
\text { Indices }\end{array}$ & $\begin{array}{c}\text { Fit indices } \\
\text { after } \\
\text { model was } \\
\text { improved }\end{array}$ & $\begin{array}{c}\text { Fit indices } \\
\text { before } \\
\text { model was } \\
\text { improved }\end{array}$ & $\begin{array}{c}\text { Best } \\
\text { fit indices }\end{array}$ & $\begin{array}{c}\text { Acceptable fit } \\
\text { indices }\end{array}$ \\
\hline $\begin{array}{l}\text { C M I N / } \\
\text { DF }\end{array}$ & 3.62 & 1.631 & $0 \leq \mathrm{X}^{2} / \mathrm{df} \leq 3$ & $3 \leq \mathrm{X}^{2} / \mathrm{df} \leq 5$ \\
\hline GFI & 0.824 & 0.921 & $\geq 0.90$ & $\geq 0.80$ \\
\hline CFI & 0.896 & 0.975 & $0.90 \leq \mathrm{CFI} \leq 1.00$ & $0.80 \leq \mathrm{CFI} \leq 0.90$ \\
\hline RMSEA & 0.151 & 0.080 & $0 \leq \mathrm{RMSEA} \leq 0.05$ & $0.05 \leq \mathrm{RMSA} \leq 0.08$ \\
\hline NFI & 0.859 & 0.940 & $\geq 0.90$ & $\geq 0.80$ \\
\hline AGFI & 0.751 & 0.851 & $0.95 \leq \mathrm{AGFI} \leq 1.00$ & $0.80 \leq \mathrm{AGFI} \leq 0.95$ \\
\hline
\end{tabular}

RMSEA: the root mean square error of approximation, NFI: normed fit index, CFI: confirmatory fit index, IFI: relative fit index, GFI: the goodness of fit index, AGFI: adjusted goodness of fit index, CMIN/DF= chi-square statistics / $D F, A G F I$ : adjusted goodness of fit index

Table 3. Item total score correlation analysis results

\begin{tabular}{|l|c|c|c|c|}
\hline & $\begin{array}{c}\text { Scale } \\
\text { average } \\
\text { when item is } \\
\text { deleted }\end{array}$ & $\begin{array}{c}\text { Scale } \\
\text { variance } \\
\text { when item is } \\
\text { deleted }\end{array}$ & $\begin{array}{c}\text { Corrected } \\
\text { item total } \\
\text { correlation }\end{array}$ & $\begin{array}{c}\text { Cronbach's } \\
\text { alpha value } \\
\text { when item is } \\
\text { deleted }\end{array}$ \\
\hline Item 1 & 79.27 & 166.947 & 0.734 & 0.852 \\
\hline Item 2 & 79.28 & 162.668 & 0.814 & 0.847 \\
\hline Item 3 & 80.20 & 172.162 & 0.576 & 0.860 \\
\hline Item 4 & 79.32 & 167.917 & 0.717 & 0.853 \\
\hline Item 5 & 79.60 & 166.566 & 0.745 & 0.852 \\
\hline Item 6 & 79.76 & 169.497 & 0.664 & 0.856 \\
\hline Item 7 & 79.74 & 172.396 & 0.625 & 0.858 \\
\hline Item 8 & 79.54 & 173.342 & 0.557 & 0.861 \\
\hline Item 9 & 79.55 & 188.876 & 0.149 & 0.885 \\
\hline Item 10 & 79.06 & 169.027 & 0.465 & 0.869 \\
\hline Item 11 & 78.46 & 172.433 & 0.558 & 0.861 \\
\hline Item 12 & 78.60 & 174.525 & 0.467 & 0.867 \\
\hline Item 13 & 80.22 & 179.244 & 0.273 & 0.882 \\
\hline
\end{tabular}

\subsection{Validity Analysis}

The KMO value is calculated as 0.817 with statistically significant Bartlett test $(\chi 2=754,863 ; p<0.001)$. The sample size is sufficient for factor analysis. The construct validity of the AFI was assessed by confirmatory factor analysis (CFA) in two stages. As a result of the CFA analysis for the threedimensional structure, which is the original structure of the AFI, it was seen that the goodness of fit index values was not in the required range. The factor loadings were low and the three sub-dimensional structures were not confirmed significantly. As the factor loadings of the 9th and 13th items were low 
in the first stage CFA results. It was decided to perform the CFA again by removing these items. In addition, the 8th item, which has the same factor (interpersonal effectiveness subdimension) as 9th and 13th items, was removed from the scale and CFA was performed for the second time. While making improvements in the model, variables that reduce compliance were identified and new covariance were created for those with high covariance among the residual values. Then, it was seen that the accepted values for the fit indices were provided in the renewed fit index calculations. According to the results of the first-level analysis, when AFI of fit indexes are examined; RMSEA, 080; GFI, 921; AGFI, 851; CFI, 975; $\chi 2$ was found to be acceptable with 1.631 values (Table 2). Factor loads of each item in the AFI ranged from 0.71 to 0.94 . The Cronbach's Alpha value for the 10 item AFI-TR confirmed by confirmatory factor analysis was 0.895 . The Cronbach Alpha values for effective action and attentional lapses subscales were 0.933 and 0.848 , respectively. Turkish modeling illustrated in supplement file defined model related 10 item Turkish form of AFI (Figure 1). There were statistically significant positive relationship between AFI total score and EORTC QLQ-C30 total score ( $r=$ $0.524, p \leq 0.001)$.

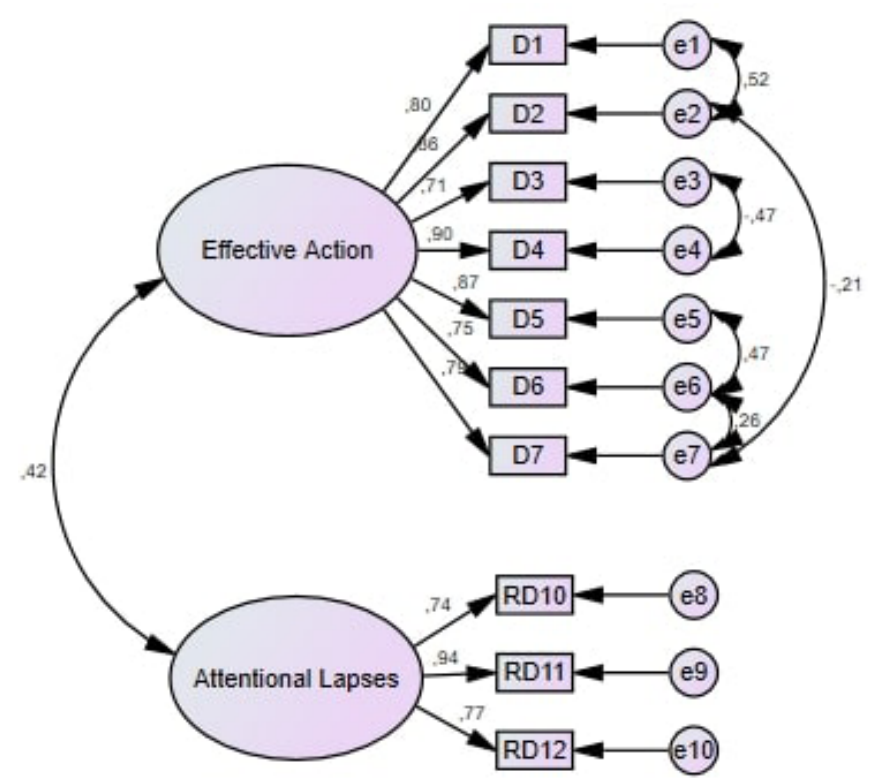

Figure 1. Model of first level multi-factor confirmatory factor analysis of $\mathrm{AFI}$

\section{DISCUSSION}

Cancer patients are at risk for cognitive problems. There are few tools that provide a subjective assessment of how daily activities supported by cognitive processes affect cancer patients. Attention Function Index (AFI) was developed to measure the perceived effectiveness of patients in daily life activities supported by attention and short memory. In this study, the validity and reliability of the Turkish version of AFI with breast cancer survivors were evaluated.

One of the reliability methods is the Cronbach Alpha coefficient. It was stated that Cronbach's alpha value should not be less than 0.50 . In studies using, AFI internal consistency was reported to be between 0.80 and 0.92 $(10,15,16,17)$. In the validity and reliability study of AFI in Brazil, the Cronbach's alpha coefficient was $0.86 ; 0.86$ for effective action; attentional lapses were found to be 0.65 and interpersonal effectiveness 0.86 (18). In our study, Cronbach's alpha coefficients were 0.89 for the total scale; effective action 0.93, attentional lapses 0.84 . These values indicate that the internal consistency of the Turkish version of AFI is acceptable.

According to the results of item-total score analysis for reliability analysis, it was found that the item-total score correlation coefficient value of items 9 and 13 was below 0.25 . In the literature, it is stated that the item-total correlation value should be higher than 0.25 for reliability (19). According to CFA results, 9th and 13th items were determined to be removed. The lower total item correlation coefficients of these items and the increase in Cronbach's alpha value when removed from the scale revealed that these items should be subtracted from the Turkish version of AFI.

Confirmatory factor analysis is performed to evaluate the accuracy of the original structure of the scale in the new sample (20). For the construct validity of a scale, the goodness of fit values performed in the confirmatory factor analysis should be at the desired level. The most commonly used fit statistics in the literature are; $\chi 2$ / df is RMSEA, SRMR, CFI, NNFI, GFI and AGFI (21). In this study, the original loadings of the AFI were tested and the factor loadings and the fit indices of the 9th and 13th items were low. In the original form of the AFI, this sub-dimension was completely omitted, as item 8, together with item 9 and 13 in the "interpersonal effectiveness" sub-dimension, could not form a single subdimension. Confirmatory factor analysis was performed for the second time for two sub-dimensions (effective action and attentional lapses). According to the results of the second CFA, the fit indices for 2-dimensional and 10-item AFI were within acceptable limits. Cronbach's alpha value for the two-factor AFI Turkish form was 0.89. Depending on cultural differences in scale adaptation research, the addition, subtraction or replacement of items may occur. If one element of the scale is not suitable for the culture to which it is adapted, the substance can be changed or removed (20). In this study, the two-factor structure (effective action and attentional lapses) of the Turkish version of AFI revealed acceptable fit indices.

The test-retest reliability analysis showed that the scale showed consistent results over time. When the test-retest results are taken into consideration, it can be said that the results are close to the original study (9). Attention affects the life significantly, including perceived social and role functions of patients $(22,23)$. In our study, the criterion validity of AFI was evaluated with the EORTC-QLQ 30 scale. In our study, a positive and significant correlation was found between AFI and 
total quality of life scale scores ( $r=0.52 ; p$-value $<0.0001)$. The correlation coefficient is interpreted as a medium between 0.50-0.69 and validity is higher than 0.7 (19). In others study evaluating the validity and reliability of AFI, it was found that there was a significant relationship between attention function and the profile of the mood state and symptom $(9,16)$.

\section{CONCLUSION}

Identifying cognitive problems is important for patientcentered cancer care. Although research has been conducted on memory and concentration problems, fewer studies have examined the impact of these perceived problems on the daily functioning of patients. The results of this research show that AFI is a high reliability and validity scale for breast cancer patients and is applicable in a clinical setting. It is important to evaluate the functional outcomes specific to the loss of short memory and basic cognitive attention systems in cancer patients in order to be aware of the problems experienced by patients due to cognitive problems. It is recommended that AFI be used in different populations in future studies and that its validity and reliability are evaluated.

\section{Acknowledgments}

The authors wish to thank all the participants in the study

\section{Funding}

The authors received no financial support for the research, authorship, and/or publication of this article.

\section{REFERENCES}

[1] Robbins TW. Cognition: The ultimate brain function. Neuropsychopharmacology 2011; 36(1): 1-2

[2] Jean-Pierre P, Winters PC, Ahles TA, Antoni M, P, Daniel Armstrong F, Penedo F, Lipshultz SE, Miller TL, Fiscella K. Prevalence of self-reported memory problems in adult cancer survivors: a national cross-section study. J Oncol Pract. 2011;8:30-34.

[3] Andreis F, Ferri M, Mazzocchi M, Meriggi F, Rizzi A, Rota L, Di Biasi B, Abeni C, Codignola C, Rozzini R, Zaniboni A. Lack of a chemobrain effect for adjuvant FOLFOX chemotherapy in colon cancer patients. A pilot study. Support Care Cancer 2013;21:583-590.

[4] Moore HC. An overview of chemotherapy-related cognitive dysfunction, or 'chemobrain'. Oncology 2014;28(9):797-804.

[5] Wefel JS, Kesler SR, Noll KR, Schagen SB. Clinical characteristics, pathophysiology, and management of noncentral nervous system cancer related cognitive impairment in adults. CA Cancer J Clin. 2015;65(2): 123-138.

[6] Janelsins MC, Kesler SR, Ahles TA, Morrow GR. Prevalence, mechanisms, and management of cancer-related cognitive impairment. Int Rev Psychiatry. 2014;26(1):102-113.
[7] Caeyenberghs $M$. Longitudinal assessment of chemotherapyinduced changes in brain and cognitive functioning: $A$ systematic review. Neuroscience and Biobehavioral Reviews 2018; 92 (2018):304-317.

[8] James W. The principles of psychology. New York: Cosimo; 2007.

[9] Cimprich B, So H, Ronis DL, Trask C. Pre-treatment factors related to cognitive functioning in women newly diagnosed with breast cancer. Psycho-Oncology 2005; 14(1):70-78.

[10] Cimprich B, Visovatti M, Ronis DL. The Attentional Function Index -a self-report cognitive measure. Psycho-Oncology 2011;20(2):194-202.

[11] Mackie MA, Van Dam NT, Fan J. Cognitive control and attentional functions. Brain Cogn. 2013; 82(3): 301-312.

[12] Lange $M$, Joly F. How to identify and manage cognitive dysfunction after breast cancer treatment. Journal of Oncology Practice 2017; 13(12): 784-790.

[13] Kitahata R, Nakajima, S Uchida H. Self-rated cognitive functions following chemotherapy in patients with breast cancer: a 6 -month prospective study. Neuropsychiatric Disease and Treatment 2017; 13:2489-2496.

[14] Demirci S, Eser E, Ozsaran Z, Tankisi D, Aras AB, Özaydemir $G$, Anacak Y. Validation of the Turkish versions of EORTC QLQ-C30 and BR23 modules in breast cancer patients. Asian Pac J Cancer Prev._2011; 12(5):1283-1287.

[15] Stark MA. Relationship of psychosocial tasks of pregnancy and attentional functioning in the third trimester. Res Nurs Health. 2001; 24:194-202.

[16] Jansen DA. Attentional demands and daily functioning among community-dwelling elders. J Community Health Nursing 2006; 23:1-13.

[17] Utne I, Grov EK, Kjerland LE, Rønning M, Rodrigues-Aranda C, Rasmussen HL, Løyland B. Translation and cultural adaptation of Attentional Functional Index. Sykepleien Forskning 2017; 12:e-64646.

[18] Dutra CKR, Guirardello EB. Validation of the Brazilian version of the Attentional Function Index. Rev Latino-Am Enfermagem. 2013; 21(2):604-609.

[19] Alpar R. Applied statistics with examples from sports, health and education sciences validity and reliability. Ankara: Detay Publishing; 2011 (in Turkish).

[20] Esin N. Data collection methods and tools \& reliability and validity of data collection tools. In: Erdoğan S, Nahcivan N, Esin $\mathrm{N}$, ed. Nursing Research. İstanbul: Nobel Medicine Publishing; 2014 (in Turkish).

[21] Kline PR. [Hypothesis testing]. Principles and Practice of Structural Equation Modeling. $3^{\text {rd }}$ ed. New York: Guilford Press; 2011. p.204

[22] Ahles TA, Root JC, Ryan EL. Cancer and cancer treatmentassociated cognitive change: an update on the state of the science. Journal of Clinical Oncology 2012; 30(30):3675-3686.

[23] Von Ah D, Tallman EF. Perceived cognitive function in breast cancer survivors: evaluating relationships with objective cognitive performance and other symptoms using the Functional Assessment of Cancer Therapy and Cognitive Function Instrument. Journal of Pain and Symptom Management 2015; 49(4): 697-706. 